\title{
Aspectos neuropsicológicos del craving por la nicotina
}

\section{Neuropsychological aspects of nicotine craving}

\author{
Miguel Ángel Muñoz*; Rocío SanuUan*; \\ M ${ }^{a}$ CaRmen Fernández-Santaella*; \\ JAIME VILA*; PEDRO MONTOYA*
}

$\mid{ }^{*} \quad$ Universidad de las Islas Baleares.
Enviar correspondencia a:

Miguel Angel Muñoz, Departamento de Psicología de la

Universidad de las Islas Baleares.

Facultad de Psicología. Universitat de les Illes Balears.

Cra. de Valldemossa, km 7.5. Palma (Illes Balears).

e-mail: miguelamuoz@yahoo.es

\section{RESUMEN}

El craving se ha definido como la motivación de autoadministrarse una sustancia que previamente ha sido consumida. Se considera que el craving es responsable del consumo compulsivo de una sustancia, así como del alto nivel de recaídas después de periodos de abstinencia. Los estudios neuropsicológicos y de imagen cerebral han identificado numerosas regiones cerebrales implicadas en el craving. En este artículo se revisan los mecanismos neuropsicológicos implicados en el craving por la nicotina, centrándose en los tres sistemas involucrados en el craving. Primero, el sistema de recompensa, responsable del desarrollo de la dependencia y del craving. Segundo, el sistema emocional y asociativo que se relaciona con el craving condicionado. Tercero, el sistema implicado en la toma de decisiones y procesos cognitivos. Además, se revisa los modelos teóricos más influyentes, como los Modelos basados en el Condicionamiento, Modelos Cognitivo-Conductuales, Modelos Cognitivos y Modelo Neurobiológico. También se discuten otros aspectos relacionados con la evaluación y tratamiento del craving, haciendo énfasis en los aspectos clínicos. Como conclusión, se acentúa la importancia de un enfoque multidisciplinar para lograr un modelo común del craving, así como para mejorar las herramientas diagnósticas y las estrategias de tratamiento.

Palabras claves: craving, tabaquismo, mecanismos neuropsicológicos, dependencia a la nicotina, modelos teóricos.

\section{ABSTRACT}

Craving has been defined as the motivation to self-administer a substance previously consumed. It has been hypothesized that craving contributes significantly to compulsive drug use and relapse after a period of abstinence in humans. Neuropsychological and brain-imaging studies have identified numerous brain regions that may be involved in craving. In this paper, the neuropsychological mechanisms of craving for nicotine are reviewed, focusing on three systems that appear to be involved in craving states. First of all, the reward system, responsible for the development of dependence and craving. Secondly, the emotional and associative system, which is related to conditioned craving. And third, the system involved in the neural basis of cognitive and decisionmaking processes. The most influential theoretical models on craving are also reviewed, including those based on conditioning mechanisms, on cognitive mechanisms and on cognitive-behavioral mechanisms, as well as the neurobiological model. Factors related to the evaluation and treatment of craving are also discussed, with particular emphasis on clinical aspects. Finally, we stress the importance of a multidisciplinary approach for achieving a common model on craving and improving the diagnostic tools and treatment strategies.

Key words: craving, smoking, neuropsychological mechanisms, nicotine dependence, theoretical models. 


\section{RELEVANCIA DEL CONSTRUCTO CRAVING EN LA ADICCIÓN AL TABACO}

E constructo craving surgió ligado a los trabajos que realizó durante la década de los años 50 Jellinek. En sus trabajos señaló que las personas con adicciones experimentan un deseo incontrolable e irresistible de consumir esa sustancia de la que son dependientes. Así, el craving se ha definido como "la motivación de autoadministrarse una sustancia que previamente ha sido consumida" (Markou, Weiss, Gold, Schulteis y Koob, 1993).

La Organización Mundial de la Salud definió el craving como un fenómeno fisiológico que se manifiesta inmediatamente después de periodos prolongados de consumo, siendo consecuencia de la abstinencia (O.M.S., 1955). Esta definición implicaba que el craving formaba parte del síndrome de abstinencia (S.A.) y que ambos debían aparecer unidos temporalmente. Fue en los años noventa, cuando se diferenció claramente el S.A. y craving. El craving aparece pronto tras la abstinencia y puede mantenerse durante un largo periodo de tiempo, mientras que el S.A. tiene una duración más limitada en el tiempo. Por ejemplo, en el caso del tabaco, el fumador puede experimentar craving pocos minutos después de haber apagado el último cigarrillo o tras años de abstinencia y puede ser producido por estímulos relacionados con la sustancia o estados emocionales (Conklin, Clayton, Tiffany y Shiffman, 2004; Hatsukami, Ebbert, Anderson, Lin, Le y Hecht, 2007).

En el ámbito del tabaquismo se considera que el craving es responsable del consumo compulsivo, de las dificultades asociadas a la abstinencia y del alto nivel de recaídas que siguen al tratamiento (Quesada, Carreras y Sánchez, 2002; Blasco, Martínez-Raga, Carrasco y Didia-Attas, 2009). El deseo irresistible de fumar juega un papel tan importante que la mayoría de los programas de tratamiento cuentan con estrategias destinadas al manejo de este impulso incontrolable o craving (Herrero y Moreno, 2004; Niaura, 2008; Kober, Kross, Mischel, Hart y Ochsner, 2010).

\section{BASES NEUROPSICOLÓGICAS DEL CRAVING POR LA NICOTINA}

Una cuestión clave en el estudio del craving es conocer las estructuras cerebrales implicadas en su aparición. El desarrollo de las técnicas de neuroimagen funcional, junto a diferentes paradigmas experimentales, han permitido identificar la existencia de una extensa red neuronal que comprende tanto estructuras corticales como subcorticales (Kalivas y Volkow, 2005; Pérez de los Cobos, Valderrama, Cervera, y Rubio, 2006, Stoehr, 2006; Rose, 2007; Sharma y Brody, 2009) (ver figura 1). Tres han sido los sistemas relacionados con el craving: sistema de recompensa (responsable del desarrollo de la dependencia y del craving), sistemas emocionales asociativos (relacionados con el craving condicionado) y sistema de toma de decisiones (relacionados con los déficits en la elección de respuestas en episodios de craving).

\section{El sistema de recompensa}

La nicotina comienza su acción a través a los receptores colinérgicos- nicotínicos, situados principalmente en las terminales presinápticas. Su activación produce una facilitación en la liberación de neurotransmisores, tales como la serotonina, noradrenalina y dopamina (Watkins, Koob y Morkou, 2000; Jiménez, Bascarán, García-Portilla, Sáiz, Bousoño y Bobes, 2004; Wise, 2004; Villegier, Salomon, Blanc, Godeheu, Glowinski y Tassin, 2006).

La zona donde se produce la activación de los receptores AchRs dentro del circuito de recompensa es el cuerpo celular del Área Tegmental Ventral (ATV). El ATV está implicado en la señalización de los estímulos críticos para la supervivencia, tales como son la reproducción y la ingesta. Esto explica por qué las sustancias psicoactivas llegan a ser tan importantes desde una perspectiva motivacional (Stoehr, 2006; Pérez de Ios Cobos, Valderrama, Cervera y Rubio, 2006). La estimulación del ATV provoca la descarga de dopamina en la Corteza Prefrontal Medial y en zonas específicas del Sistema Límbico. La dopamina ha demostrado un papel crucial en los procesos de reforzamiento implicados en la adquisición y consumo de nicotina (Balfour, 2005; Zhang, Liang, Siapas, Zhou y Dani, 2009). Así, estudios con animales en los que se condiciona la administración de nicotina a un determinado lugar señalan que el animal permanece durante más tiempo en la zona de administración (Wooltorton, Pidoplichko, Broide y Dani, 2003; Zanetti, Picciotto y Zoli, 2007).

Dentro de las estructuras a las que proyecta el ATV, el Núcleo Accumbens está relacionado con la experiencia subjetiva de refuerzo y gratificación, así como con la anticipación del placer (Stoehr, 2006). La nicotina, al igual que otras drogas de abuso, aumenta la concentración de dopamina en la zona ventromedial del Núcleo Accumbens. Las investigaciones demuestran que la nicotina provoca una liberación selectiva de dopamina en la cubierta del Núcleo Accumbens y que ésta es dependiente de la dosis (Zhang et al, 2009; Zanetti, Picciotto y Zoli, 2007). Las proyecciones de las neuronas ubicadas en el Núcleo Accumbens, alcanzan la región de la Amígdala y la Corteza Frontal. La Amígdala, a su vez, presenta conexiones con otras regiones cerebrales que controlan las emociones y el estrés. Por otro lado, la corteza frontal integra la información adquirida a través de los sentidos, permitiendo realizar asociaciones entre la información ambiental y la recompensa.

\section{Mecanismos emocionales y asociativos}

Los mecanismos emocionales y asociativos explican cómo se produce el aprendizaje pavloviano entre estímulos neutrales y los efectos de la nicotina; y por qué se produce el craving ante estos estímulos condicionados (Drummond, Tiffany, Glautier y Remington, 1995; Drobes, 2002). Esto supone un procesamiento de abajo-arriba en el cual están implicados la Amígdala, el Hipocampo y el Circuito Estriado-TalámicoCortical (Chiamulera, 2005; Weiss, 2005).

La Amígdala es la encargada de procesar el significado emocional de los estímulos evocadores de craving y disparar 


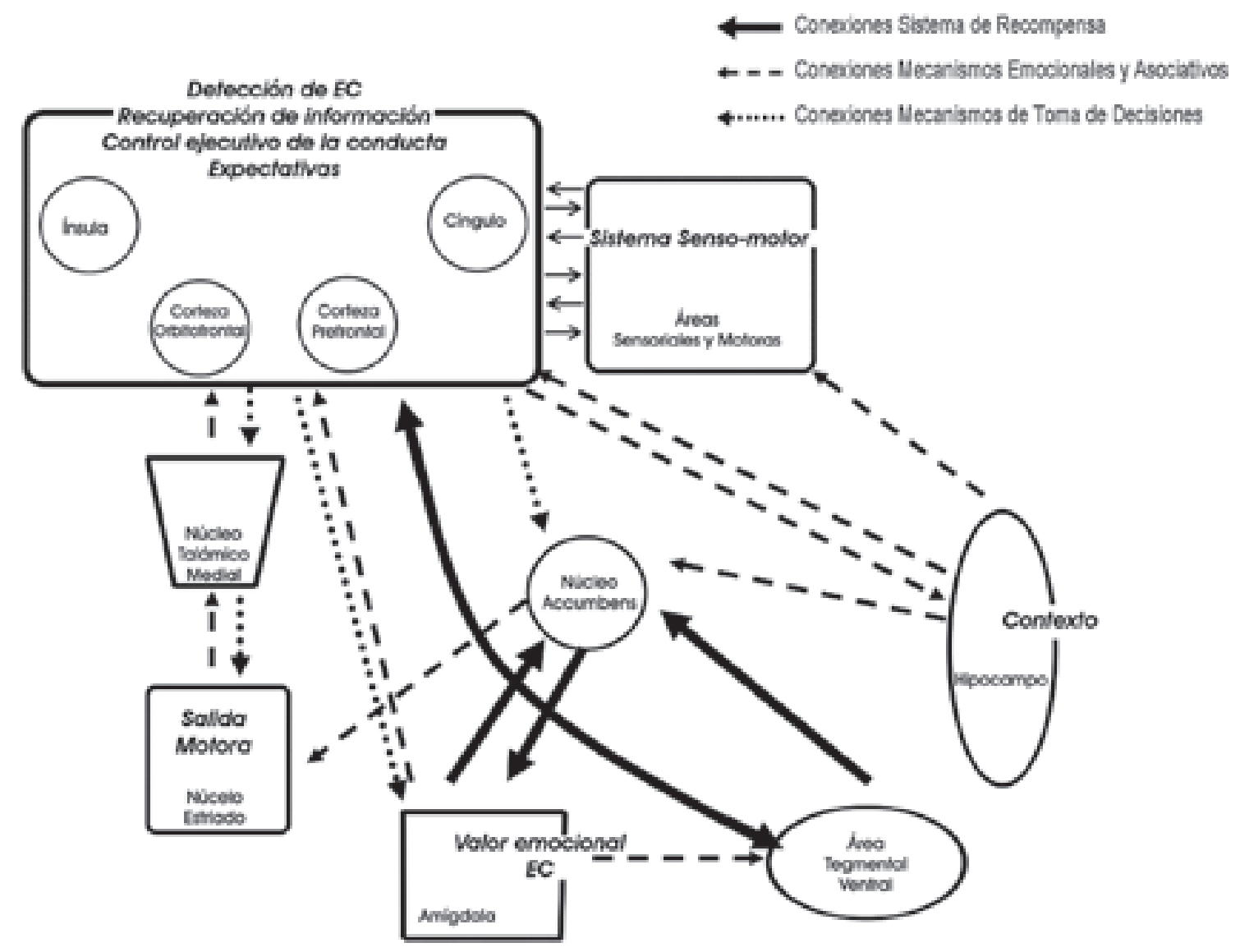

Figura 1. Estructuras y conexiones cerebrales implicadas en el Craving.

la respuesta psicológica y fisiológica que motiva la conducta (Chiamulera, 2005). Los estudios realizados con Tomografía por Emision de Positrones (PET) y Resonancia Magnética funcional (fMRI) en fumadores expuestos a estímulos condicionados con la sustancia, señalan que el nivel de craving autoinformado se relaciona con la activación en la Amígdala (Due, Huettel, Hall y Rubin, 2002). Dentro de ésta, hay que diferenciar la región Basolateral y los Núcleos Centromediales. La primera estaría relacionada con el condicionamiento a señales que predicen el consumo y, por tanto, relacionadas con la respuesta de craving, así como con la valoración del refuerzo durante la respuesta instrumental (Dunn y Everitt, 1988; Di Ciano y Everitt, 2004). Los Núcleos Centromediales estarían relacionados con el aprendizaje instrumental para obtener la sustancia proyectando sobre el Sistema Endocrino y el Hipotálamo. Esto proporciona la ruta para que la Amígdala tenga acceso al control autonómico, endocrino y a la conducta refleja implicada en la respuesta emocional (Everitt y Robbins, 2005; Davis, 1992).

La formación hipocampal presenta conexiones aferentes con la cubierta del Núcleo Accumbens y con la Corteza Sensomotora, y conexiones aferentes y eferentes con la Corteza
Frontal (Chiamulera, 2005; Kelley, 2004). Los estudios con animales señalan que el Hipocampo está implicado en la producción del craving contextual más que con el craving condicionado a estímulos discretos (Placzek, Zhang y Dani, 2009). Esto indicaria una especificidad cerebral en la detección de estímulos asociados a la nicotina; mientras que la Amígdala codificaría estímulos concretos que predicen el consumo, el Hipocampo únicamente indicaría situaciones contextuales asociadas al mismo, siendo ambas funciones complementarias (Selden, Everitt, Jarrard y Robbins, 1991; Everitt y Robbins, 2005). Así, en términos psicológicos, el Hipocampo proporciona el "contexto de fondo" que facilita la respuesta al estímulo.

Los estudios de neuroimagen que han empleado fumadores abstinentes o dosis de nicotina para inducir craving, señalan que la activación del circuito Estriado-Talámico-Cortical es el mecanismo neural por el cual la motivación se convierte en acción, estando implicado en la saliencia de los estímulos reforzadores (Livingstone y Wonnacott, 2009). El Núcleo Estriado desempeña un papel importante en la activación de conductas motoras apetitivas, como la búsqueda y localización de reforzadores primarios (Joel y Weiner, 2000). Fun- 
cionalmente se diferencia dos regiones, el Estriado Ventral y el Estriado Dorsal. El primero, recibe aferencias indirectas a través del Núcleo Accumbens procedentes de la Amígdala Basolateral y la Formación Hipocampal y proyecta hacia la Corteza Frontal a través del Tálamo Dorsomedial (Groenewegen, Berrendees y Haber, 1993; Napier, Mitrovic, Churchill, Klitenick, Lu y Kalivas, 1995). Este circuito se ha identificado con el mecanismo que controla la conducta instrumental, dirigido por el valor hedónico, para conseguir la sustancia (Everitt y Robbins, 1992). El Estriado Dorsal estaría implicado en la transición del consumo dirigido por el valor hedónico de la sustancia al consumo compulsivo de la misma. Presenta densas proyecciones sobre la corteza frontal a través del tálamo (Baxter y Murray, 2002; Everitt, Parkinson, Olmstead, Arroyo, Robledo y Robbins, 1999; Robbins y Everitt, 1996), así como una vía de retorno eferente desde la corteza frontal al Estriado Dorsal, a través de los núcleos caudados y putamen (Cardinal, Parkinson, Hall y Everitt, 2002).

\section{Mecanismos de toma de decisiones}

Los mecanismos de toma de decisiones explicarían los problemas atencionales, cognitivos y las dificultades para mantenerse abstinente asociados al craving (Goldstein y Volkow, 2002; Lim, Pae, Joo, Yoo, Choi, Kim y Lee, 2005). Esto supone un procesamiento de arriba-abajo que, partiría desde las áreas corticales para modular el procesamiento sensorial hasta el control motor dirigido a la obtención de metas. Las áreas corticales cuya activación correlaciona con los autoinformes de craving por la nicotina en estudios de neuroimagen son: Corteza Cingulada, Corteza Prefrontal y la Ínsula (Brody, Maldelkern, London, Childress, Lee, Bota y Jarvik, 2002; Wilson, Sayette y Fiez, 2004;).

La Corteza Cingulada está implicada en el procesamiento de las demandas cognitivas y atencionales ante estímulos condicionados al consumo. La Corteza Cingulada presenta densas proyecciones hacia la Amígdala y el Núcleo Accumbens (Pitkänen, 2000), modulando el procesamiento de la información emocional y motivacional y guiando la conducta para la obtención de la sustancia (Shidara y Richmond, 2002). En tareas de condicionamiento clásico apetitivo, se ha encontrado que la lesión del Cíngulo atenúa las conductas de aproximación a los estímulos positivos, aunque no las extingue, tal y como sucede con las lesiones de la Amígdala Basolateral (Parkinson, Crofts, Mc Guigan, Tomic, Everitt y Roberts, 2000).

La Corteza Prefrontal se relaciona con la memoria operativa $y$, por tanto, con la capacidad para mantener activa la información relativa a las características contextuales o situacionales del consumo (Miller y Cohen, 2001; Matsumoto, Suzuki y Tanaka, 2003; Roesch y Olson 2004). La zona orbitofrontal conecta con áreas mesolímbicas, haciendo posible integrar la información emocional y motivacional con las representaciones mantenidas en la memoria de trabajo. A igual que el Núcleo Accumbens, la Corteza Prefrontal recibe conexiones dopaminérgicas del ATV, de lo que se deduce su participación en procesos de aprendizaje a nuevos reforzadores, mediante la liberación de dopamina. De igual modo que sucede en el Núcleo Accumbens, las drogas de refuerzo producirían una señal domapinérgica en la zona orbitofrontal, produciendo un sobreaprendizaje de los estímulos asociados con la sustancia de consumo, aumentando su saliencia sobre otros estímulos y provocando la conducta compulsiva de consumo (Berridge, 2007). Como ya hemos señalado, el sistema Estriado-Talámico-Frontal se relaciona con la conducta compulsiva. Este circuito finaliza en la Corteza Orbitofrontal, que sería en última instancia la responsable del control conductual. Diferentes estudios indican que la impulsividad conductual observada en fumadores bajo estado de craving se debe a la ausencia de inhibición de la Corteza Orbitofrontal sobre la conducta, (Field, Rush, Cole y Goudie, 2007; Lim et al, 2005; Gloria, Angelos, Schaefer, Davis, Majeskie, Richmond y Baker, 2009).

La Ínsula se relacionaría con la representación del estado homeostático del organismo en situaciones de abstinencia, así como con la inhibición del control de la conducta en estado de craving (Gray y Critchley, 2007; Chiamulera, 2005). Naqvi, Rudrauf, Damasio y Bechara (2007) presentan el caso de 19 fumadores que, tras sufrir lesiones en la ínsula, dejaban de fumar fácilmente manteniéndose abstinentes. Según estos autores, al dañar la ínsula, se bloqueaba la consciencia de las señales corporales indicativas de necesidad de nicotina, así como de las sensaciones que anticipan los efectos placenteros de la sustancia, dejando intacto las sensaciones de placer hacía reforzadores incondicionados tales como la comida. Naqvi y colaboradores señalan que la ínsula estaría relacionada con el aprendizaje fisiológico de estados agradables, pero que la comida, al ser un estímulo incondicionado agradable no produciría este tipo de aprendizaje (Naqvi, Rudrauf, Damasio y Bechara, 2007).

\section{MODELOS EXPLICATIVOS SOBRE LAS CAUSAS Y FUNCIONES DEL CRAVING}

Se han propuesto cuatro grandes aproximaciones teóricas que tratan de explicar las causas y funciones del craving en fumadores (Tiffany, 1990; Antón, 1999; Drummond, 2001): Modelos basados en el Condicionamiento, Modelos Cognitivo-Conductuales, Modelos Cognitivos y Modelos Neurobiológicos.

\section{Modelos basados en el condicionamiento}

El Modelo de la Abstinencia Condicionada (Ludwig y Wikler, 1974) asume que el craving es desencadenado por el síndrome de abstinencia. El consumo reiterado de nicotina implica periodos de abstinencia involuntaria que desencadenan una serie de manifestaciones físicas y psicológicas de carácter negativo, las cuales se asocian con señales contextuales. Como consecuencia, surge el craving, es decir, una motivación para evitar el malestar inducido por las claves contextuales de la abstinencia. Mientras que el Modelo de Abstinencia Condicionada predice que el deseo podría ser más fuerte ante situaciones emparejadas con la abstinencia, el Modelo de Tolerancia Condicionada o Respuesta Compen- 
satoria (Siegel, 1979) propone que son las situaciones emparejadas con la conducta de fumar las que provocan el estado motivacional de craving. De este modo, en presencia de claves ambientales de consumo, el organismo emite respuestas condicionadas compensatorias, cuya función es preparar al organismo para el consumo y que suponen un desequilibrio homeostático. El craving se concibe como un tipo de respuesta condicionada anticipatoria, que induciría la búsqueda de nicotina para restablecer ese equilibrio.

El Modelo de Incentivo Condicionado o Modelo Apetitivo (Stewart, De Wit y Eikelboom, 1984; Wise y Bozarth, 1987) propone que el craving surge por el deseo de experimentar los efectos estimulantes del tabaco, siendo desencadenado por la presencia de estímulos condicionados al consumo y a sus efectos reforzantes. Desde esta perspectiva, se enfatiza el papel de los efectos reforzantes de la nicotina como la base que motiva el consumo y que desencadena el craving. Los estímulos fuertemente asociados al consumo y por tanto a los efectos reforzantes, se convierten a través de procesos de condicionamiento en desencadenantes de expectativas positivas. Estas expectativas activarian el craving (estado motivacional central dirigido a la búsqueda de nicotina).

\section{Modelos cognitivo-conductuales}

Se han propuesto dos modelos cognitivo-conductuales: el Modelo del Etiquetado Cognitivo y el Modelo de Expectativas de Resultado.

El Modelo del Etiquetado Cognitivo implica que los estímulos relacionados con el tabaco pueden generar activación condicionada, que a su vez activan los procesos mentales, que identifican la situación como una escena para fumar. Como resultado de esta respuesta cognitiva, el fumador interpreta las reacciones fisiológicas como craving (Poulos, Hinson y Siegel, 1981; Ludwing y Wikler, 1974). Simplemente, el fumador piensa: "me siento activado y estoy en una situación en la que normalmente fumo, por consiguiente, esta sensación debe ser que deseo un cigarrillo".

El Modelo de Expectativas de Resultado de Marlatt (1985) mantiene que las señales contextuales activan las expectativas sobre los efectos de la sustancia y que éstas influirán en la conducta. Las expectativas tienen dos componentes esenciales: un componente informativo y un componente motivacional. El componente informativo representa las creencias específicas sobre la nicotina y sus efectos, el componente motivacional refleja el deseo por experimentar los efectos positivos de la sustancia (sentir los efectos generados por las expectativas). El Modelo de Expectativas de Resultado también distingue entre "craving" e "impulso". El craving sería la sensación subjetiva (deseo, necesidad, arousal físico, arousal emocional) de deseo por conseguir el estado psicológico inducido por las drogas; el "impulso" sería el determinante conductual de búsqueda y consumo de la sustancia. El "impulso" se conceptualiza como la consecuencia instrumental del craving, la intención conductual para verse implicado en una conducta consumatoria específica. El objetivo último del impulso es reducir el estado que lo ha instigado (craving).

\section{Modelos cognitivos}

Se han propuesto dos modelos cognitivos: el Modelo del Doble Afecto y el Modelo del Procesamiento Cognitivo.

El Modelo del Doble Afecto (Baker, Morse y Sherman, 1986) propone que el craving está controlado por sistemas complejos de procesamiento emocional que influyen en las respuestas fisiológicas, en los auto-informes de craving, en la emoción y en la conducta de consumo de nicotina. El argumento de los investigadores es que ese deseo puede reflejar el funcionamiento de dos sistemas afectivos, uno negativo y otro positivo. El afecto negativo podría activarse por un estado emocional negativo o por señales asociadas con episodios de abstinencia. Cuando se activa el sistema negativo induce la experiencia de craving, el afecto negativo y reacciones fisiológicas que son similares a las producidas por la abstinencia tabáquica (cansancio, falta de concentración...). Reciprocamente, el afecto positivo de craving es asociado con las emociones agradables y reforzantes de los efectos del tabaco. Este sistema de deseo es activado por los estados emocionales positivos y las señales contextuales asociadas al hábito de fumar. La activación de este sistema induce el deseo, la conducta de búsqueda de tabaco, el afecto positivo y respuestas fisiológicas similares a los efectos estimulantes del tabaco.

El Modelo del Procesamiento Cognitivo (Tiffany, 1990, 1995) propone que, después de una larga historia de consumo, muchas de las acciones implicadas en la conducta de fumar se vuelven automáticas. Así, las conductas implicadas en el hábito de fumar son relativamente rápidas y eficientes, difíciles de impedir en presencia de estímulos desencadenantes, fluidas y sin necesidad de control consciente. Toda esta información es almacenada en la memoria a largo plazo, formando una unidad (acción planificada automática o plan de acción), la cual contiene la información para la iniciación y coordinación de una secuencia compleja de conductas. Así, el fumador presentará un alto nivel de automatización. Sin embargo, si decide abandonar el consumo o no tiene en ese momento tabaco, se verá obligada a poner en práctica conductas alternativas de consumo. Estas conductas estarian controladas por procesos no automáticos y se caracterizan por ser lentos, flexibles, intencionados, demandantes de esfuerzo cognitivo y limitados por la capacidad cognitiva. La activación de estos procesos dará lugar a la experiencia de craving, y producirá interferencia con otras tareas que precisen un control consciente, como tareas difíciles o que se están aprendiendo (Sayette y Hufford, 1994; Rosse, Johri, Kendrick, Hess, Alim, Miller y Deutsch, 1997).

\section{Modelos Neurobiológicos}

La teoria de Sensibilización al Incentivo, surge por las limitaciones de los modelos clásicos sobre las adicciones. Robbinson y Berridge (1993), sostienen la existencia de dos procesos psicológicos con sustratos neurales diferenciados en la generación de la adicción: "el gustar" ("Liking"), responsable de los efectos hedónicos de la sustancia y "el desear" ("Wanting" o "Craving"), responsable del comportamiento 
motivado. En las primeras fases de uso de la sustancia, el consumo estaría mediado por los efectos placenteros y las expectativas agradables hacia la sustancia ("Liking"), más que por el deseo irresistible de consumirla ("Wanting"). Con el consumo repetido, el sistema neuronal que media el "Wanting" se sensibiliza, apareciendo un deseo intenso o craving ante estímulos que predicen el consumo (Berridge, 2007). Por el contrario, los mecanismos neuronales responsables del "Liking" no son sensibilizados, produciéndose la progresiva separación de estos dos procesos y pudiendo llegar a la situación de alto craving y bajo afecto positivo. Que un estímulo ha sido sensibilizado significa que ese estímulo y sus representaciones se han vuelto altamente atractivas y deseadas (Berridge, Robinson y Aldridge, 2009). Así, la visión de un cigarrillo, llega a asociarse con sus propiedades reforzantes, es decir, el sistema nervioso se encuentra sensibilizado a las propiedades reforzantes del incentivo y a los estímulos que predicen su aparición.

Bajo esta visión, el craving es debido a la sensibilización de las estructuras cerebrales implicadas en el refuerzo. Como indicamos anteriormente, el Sistema Mesolímbico es el responsable de los efectos reforzantes de las drogas en general y de la nicotina en particular. Cada vez que se consume tabaco se produce un aumento en los niveles de dopamina en las vías mesolímbicas. Con el paso del tiempo y el consumo repetido, se producirá la neuroadaptación de este sistema a la dopamina, provocando la sensibilización de las estructuras mesolímbicas (Robinson y Berridge, 1993; Berridge y Robinson, 1998). La sensibilización neural y la neuroadaptación a la dopamina, provocará que estas vías puedan ser reactivadas fácilmente, incluso mucho tiempo después de haber dejado de fumar. Así, las señales condicionadas con el tabaco, pueden desencadenar craving por la nicotina y el restablecimiento de la conducta de fumar, incluso después de un largo periodo de abstinencia.

\section{EVALUACIÓN SUBJETIVA DEL CRAVING POR LA NICOTINA}

Las medidas de autoinforme han sido el método comúnmente empleado para evaluar si una persona experimenta craving (Tiffany, 1997; Shiffman, West y Gilbert, 2004). Esto no es sorprendente si tenemos en cuenta que, en general, los autoinformes de craving son medidas que pueden tener una alta validez, ser construidas con relativa facilidad y ser fáciles de administrar. Sin embargo, también presentan dificultades con relación a su correcta elaboración psicométri- ca y a los problemas asociados a la deseabilidad social y a la inexactitud al informar de experiencias pasadas (Sayette, Shiffman, Tiffany, Niaura, Martin y Shadel, 2000).

Se han elaborado numerosos tipos de autoinformes de craving por el tabaco con diferentes características (para una revisión ver Sayette et al, 2000). Destacan dos tipos, los multidimensionales y los unidimensionales. Los primeros se basan en los contenidos semánticos empleados por los consumidores para describir su estado de deseo, así como las sensaciones o emociones asociadas a la experiencia de craving. Shadel y colaboradores (2001) pidieron a un grupo de fumadores en tratamiento que describieran su "experiencia habitual" de craving. Los resultados revelaron que todos los participantes hacian referencia a cinco dimensiones o categorias: fisiológica, afectiva cognitiva, conductual y analogías para describir el craving. Basándose en estas categorias, Tiffany (1992) propuso medir el craving en función de cinco dimensiones: deseo de consumir, intención de consumir, anticipación de los efectos positivos, anticipación de alivio del síndrome de abstinencia o la disforia y percepción de falta de control. Este planteamiento teórico llevó a la elaboración del "Questionnaire on Smoking Urges (OSU)" (Tiffany y Drobes, 1991), un instrumento que permite evaluar el craving tanto en el momento actual (en su versión craving-estado) y evaluarlo durante la última semana (en su versión cravingrasgo).

A diferencia de las escalas multidimensionales, las escalas unidimensionales presentan la ventaja de una fácil y rápida aplicación, importante en el caso de ensayos clínicos que precisen una evaluación repetida de esta variable o para la evaluación del craving evocado por estímulos condicionados (Trujols, Tejero y Siñol, 2003). Entre los cuestionarios unidimensionales para medir el craving, destaca la "Visual Analog Scale" (VAS) o Escala Analógica Visual (EAV) (Bond y Lader, 1974). Consiste en una línea continua de $10 \mathrm{~cm}$ flanqueada por las palabras "mucho" y "nada", donde el fumador indica en qué parte de esta línea situaría el deseo que experimenta. Aunque esta escala es muy utilizada para evaluar el craving por cualquier sustancia, no existen estudios sobre la fiabilidad y la validez de los datos recogidos. En esta línea, Muñoz et al., (2009) han elaborado una escala pictográfica monopolar que permite evaluar el craving ante estímulos condicionados con el tabaco (Figura 2). La escala representa 5 figuras humanoides que representaban diferentes grados de deseo. Las figuras van desde una figura inexpresiva con la boca pequeña (bajo deseo) hasta una figura con la boca abierta (alto deseo), evaluándose en un rango de 1 a 9. La Escala Pictográfica de Deseo (PAD) presenta altas correlacio-

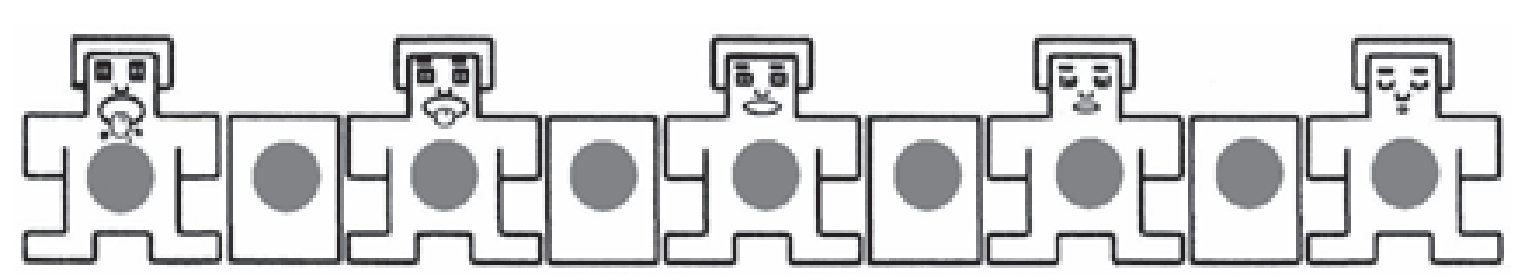

Figura 2. Escala Pictográfica de Deseo (PAD) 
nes cuando se compara con otros cuestionarios multidimensionales de craving, así como una alta validez discriminante ante estímulos condicionados con la sustancia (Muñoz, Martínez, Fernández, Cepeda-Benito y Vila, 2010).

\section{FARMACOLOGÍA Y ESTRATEGIAS PARA EL MA- NEJO DEL CRAVING POR LA NICOTINA}

Como queda de manifiesto, uno de los principales retos a los que debe hacer frente el fumador a lo largo de su vida es al craving. Esto ha llevado al desarrollo de fármacos derivados de la nicotina, que resultan menos nocivos y adictivos que el tabaco. Obviamente, estos sustitutos también afectan a los niveles de craving por el tabaco, a pesar de no haber sido diseñados para tratar el deseo por consumir. Así, en los tratamientos se suelen incluir elementos como parches 0 chicles de nicotina que, se supone, actúan sobre los niveles de nicotina en sangre y que, por tanto, son efectivos en la disminución del craving (Cepeda-Benito, 1993). En sus diferentes presentaciones (chicle, parche, inhalador, pulverizador nasal, pastilla sublingual y comprimidos para chupar) los sustitutos de la nicotina son fármacos de primera elección para el evitar el consumo de tabaco (Sáiz et al, 2004; Fiore, Jaén, Baker, Bailey, Benowitz, Curry y Wewers, 2008). Como ventaja presenta que reduce los efectos adversos de la abstinencia, disocia la conducta de fumar con los efectos de la nicotina (Henningfield, 1995) y no contiene los elementos cancerígenos que se encuentran en el humo del cigarrillo (Benowitz, 1998; West, 2000). Sin embargo, a pesar de reducir los efectos fisiológicos negativos a corto plazo, el craving continúa manifestándose a lo largo del tiempo, siendo aconsejable combinarlo con tratamiento psicológico (Benowitz, 2008a; Fiore et al, 2008).

A pesar de no estar claro su funcionamiento, el Bupropion (Zyntabac) parece aumentar los niveles de dopamina y norepinefrina actuando como antagonista de la nicotina por su capacidad para bloquear las subunidades $\alpha 3 \beta 2$ y $\alpha 3 \beta 4$ de los receptors colinérgicos nicotínicos (Lerman et al, 2004; Benowitz, 2008b; Xi, Spiller y Gardner, 2009). A igual que la terapia sustitutiva de la nicotina, el Bupropion está recomendado como fármaco de primera línea en el tratamiento del tabaquismo (Fiore et al, 2008), mostrando aproximadamente el doble de éxito en comparación con el placebo en estudios de meta-análisis (Henningfield, Fant y Buchhalter, 2005). La duración del tratamiento oscila entre 8-12 semanas, aunque no está contraindicado para el uso más prolongado (Sociedad Española de Psiquiatría, 2003).

La Vareniclina es un agonista de la subunidad $\alpha 4 \beta 2$ y $\alpha 7$ del receptor colinérgico nicotínico (Mihalak, Carroll y Luetje, 2006; O'Connor, Parker, Rollema y Mead, 2010). Los estudios sugieren que la Vareniclina estimula el flujo de dopamina en el núcleo accumbens, observándose una atenuación de las propiedades reforzantes de la nicotina (Mihalak, Carrol y Luetje 2006; Tonstad, 2006). Por su acción agonista, disminuye el craving y bloquea el efecto de satisfacción y recompensa que produce el tabaco (Tonstad, 2006; Jorenby et al, 2006). La posología indicada (Fiore et al, 2008) señala que la Vareniclina debe ser tomada una semana antes del abandono del consumo de tabaco, una dosis de $0.5 \mathrm{mg}$ durante los primeros 3 días, seguido por dos dosis de $0.5 \mathrm{mg}$ durante los siguientes 4 dias. Durante los siguientes 3 meses la dosis indicada es de 2 dosis de $1 \mathrm{mg}$ por día. Los pacientes deben abandonar el consumo de tabaco en el día 8, cuando la dosis se aumenta a $2 \mathrm{mg} / \mathrm{di}$. Por último, Ebbert y colaboradores (2009) han apuntado que el uso de Vareniclina junto al Bupropion podría aumentar la tasa de abstinencia en comparación con el uso de Vareniclina únicamente.

Algunos estudios señalan que los antidepresivos tricíclicos que inhiben la recaptación de noradrenalina y serotonina, podrian facilitar el abandono del hábito tabáquico. La Nortriptilina, ha obtenido resultados prometedores, señalando que su uso combinado con parches de nicotina aumenta la tasa de abandono, comparado con el uso de sustitutos del tabaco únicamente (Prochaska, Delucchi, y Hall, 2004). Sin embargo no está claro si es mejor su uso con sustitutos de la nicotina o junto a los mismos (Hughes, Otead y Lancaster, 2005). En una revisión sobre el tema, Hughes, Stead, y Lancaster, (2007) señalan que la eficacia de la Nortriptilina es similar a la del Bupropion y a la de los sustitutos de nicotina, sin embargo sus posibles efectos adversos sobre la salud no han sido todavía suficientemente investigados. Estas debilidades han Ilevado a no considerar a la Nortriptilina un fármaco de primera elección para el tratamiento del tabaquismo (Fiore et al, 2008).

La Buspirona es un ansiolítico que mitiga el estado de inquietud asociado al craving, actuando sobre los receptores serotoninérgicos (Pinet, 2003). Aunque se ha mostrado eficaz en personas con elevados niveles de ansiedad previa a la cesación tabáquica (Cinciripini et al, 1995), en un metaanálisis realizado por Schneider y colaboladores (1996), concluyen que no existen suficientes evidencias que demuestren su eficacia a largo plazo.

La fluoxetina es un inhibidor selectivo de la recaptación de serotonina, indicado para tratar diferentes trastornos del estado de ánino. Los estudios realizados hasta la fecha en el tratamiento del tabaquismo no han sido concluyentes. Niaura y colaboradores (2002), informan de la ausencia de diferencias significativas en fumadores tratados con fluoxetina durante 10 semanas en comparación a pacientes controles. Por otro lado, otros estudios señalan que pudiera ser útil en la regulación del aumento de peso que sigue al abandono del consumo de tabaco (Parsons, Shraim, Inglis, Aveyard y Hajek, 2009), especialmente en pacientes que no dejan de fumar por su miedo a engordar y en el grupo de mujeres (Jané, 2004; Muñoz, Baena y Cepeda-Benito, 2006). Los estudios clínicos realizados con Doxepina, han sido escasos (Murphy, Edwards, Downs, Ackerman y Rosenthal, 1990). Otro fármaco candidato para el tratamiento del craving por el tabaco es la Sertralina. Se trata de un fármaco antidepresivo, cuyo mecanismo de acción es inhibir la recaptación de serotonina y noradrenalina (Frazer, 2001). Aunque los estudios demuestran que reducen de manera significativa el craving en consumidores de cocaína y alcohol (Pettinati, Volpicelli, Kramzler, Luck, Rukstalis y Cnaan, 2000; Winhusen, Somoza, Harrer, Mezinskis, Montgomery, Goldsmith y Elkashef, 2005), 
los estudios con fumadores son escasos y poco prometedores (Covey, Glassman, Stetner, Rivelli y Stage, 2002). La clonidina es un agonista de los receptores noradrenégicos $\alpha 2$ usado en el tratamiento de la hipertensión. Diferentes ensayos clínicos (Glassman, Covey, Dalack, Stetner, Rivelli, Fleis y Cooper, 1993; Nana y Praditsuwan, 1998) y metaanálisis (Gourlay y Benowitz, 1995; Nides, 2008) ponen de manifiesto que la clonidina es más eficaz que el placebo en la cesación del hábito tabáquico, aunque la evidencia sobre su eficacia es aún limitada, por lo que no ha sido aprobada por la FDA (U.S. Food and Drug Administration) para el tratamiento del craving. Se cree que la eficacia de la clonidina como anticraving es debido a sus efectos sedativos, lo que reduce la ansiedad asociada al deseo por fumar (Benowitz, 2008b; Nides, 2008). Sin embargo, los efectos adversos limitan su uso, siendo considerado un tratamiento de segunda línea en la cesación del tabaquismo (Fiore et al, 2008; Ray, Tyndale y Lerman, 2009).

La mayoría de estos tratamientos farmacológicos buscan mitigar los síntomas fisiológicos que se experimentan en las primeras fases del tratamiento. Sin embargo, el craving puede experimentarse incluso después de años de abstinencia, pudiendo precipitar la recaída (Allen, Bade, Hatsukami y Center, 2008). El desarrollo de técnicas psicológicas y el entrenamiento en habilidades de afrontamiento puede ser una herramienta eficaz que contribuya, no sólo a superar el craving en las primeras fases del abandono del consumo tabáquico, sino también a mantener la abstinencia durante largos periodos. Sin embargo, el desarrollo de técnicas específicas para afrontar el craving ha sido transversal a otros aspectos relacionados con el tratamiento, como la preparación para dejar de fumar, las habilidades para rechazar ofrecimientos o control de situaciones de riesgo. En cualquier caso, la terapia psicológica siempre está indicada para el tratamiento del tabaquismo, ya sea sólo o combinado con el uso de fármacos (Fiore et al, 2008). Evitando ser exhaustivos, señalar que la puesta en marcha de un programa deportivo ha sido una práctica indicada para el control del craving (Ashelman, 2000; U.S.D.H.H.S., 2008). Diferentes estudios señalan reducciones del craving autoinformado en episodios puntuales de craving si los participantes en ese momento realizan alguna actividad física (ver revisión de Ussher, Taylor y Faulkner, 2008). Aunque no está claro cuales pueden ser los mecanismos implicados a nivel fisiológico, Taylor y Katomeri (2007) apuntan a que puede ser debido a una reducción en la tensión arterial, mientras que algunos estudios con fMRI (Janse van Rensburg, Taylor y Hodgson, 2007; Janse van Rensburg, Taylor y Hodgson, 2009) sugieren que las áreas cerebrales implicadas en el craving son menos activadas después del esfuerzo físico. En cualquier caso, aspectos como que tipo de actividad física es mejor (moderada o intensa) y qué tipo de programa puede resultar más beneficioso, son preguntas que aún queda por responder. Desde el modelo cognitivo, la intervención para el manejo del craving se centraría en la modificación de las creencias disfuncionales vinculadas al abandono del consumo de nicotina y a la sintomatología del craving. Así, la terapia cognitiva persigue que el paciente sea consciente que el craving está mediado por las creencias y las expectativas que tiene sobre el con- sumo de tabaco. La terapia se basará, por tanto, en la modificación de estas creencias, reemplazándolas con creencias sobre autocontrol más adaptativas (Merikle, 1999; Iraurgi y Corcuera, 2008). Otras técnicas empleadas como forma de resistencia al craving son las denominadas estrategias cognitivas de afrontamiento (Shiffman, 1984), que consistente en entrenar al paciente en detener su pensamiento en situaciones de craving y pensar en los efectos negativos que el consumo de tabaco tiene en su vida, así como los efectos positivos de mantenerse abstinente (Kober, Kross, Mischel, Hart y Ochsner, 2010). A lo largo de las últimas tres décadas, ha surgido un creciente interés por los tratamientos psicológicos basados en el "mindfulness" como forma de manejar el craving por sustancias (ver Blasco, Martínez, Carrasco y Didia-Attasen, 2008). Aunque hasta la fecha, la eficacia de esta técnica es limitada, algunos estudios parecen apuntar que podrían ser eficaces en el manejo del craving (Gifford, Kohlenberg, Hayes, Antonuccio, Piasecki, Rasmussen-Hall y Palm, 2004; Davis, Fleming, Bonus y Baker, 2007). Se ha hipotetizado que la eficacia del mindfulness en el manejo del craving sería debido a una mejora de los procesos de control y la reducción de la conducta automática de fumar (Vidrinea et al, 2010), aunque también se ha apuntado a la posibilidad de una mejora en la regulación emocional y a un mayor afecto positivo (Brown y Ryan, 2003; Baker, Piper, McCarthy, Majeskie y Fiore, 2004). Finalmente, entre las técnicas conductuales se encuentra el control estimular en periodos críticos de craving (evitar lugares y actividades relacionados con el consumo de tabaco) y la exposición con prevención de respuesta. La exposición con prevención de respuesta ha sido extensamente empleada en contextos psicológicos para el tratamiento de fobias y trastornos de ansiedad, e incluso trastornos de la conducta alimentaria. En el contexto del craving por el tabaco esta técnica ha sido menos empleada, por lo que hay pocos datos sobre su efectividad (e.g. Niaura et al, 1999). Aunque la exposición con prevención de respuesta sola o unida a terapia cognitiva (Niaura, Abrams, Shadel, Rohsenow, Monti y Sirota, 1999) ha señalado algún efecto, no hay evidencia de su mayor efectividad cuando se compara con terapia cognitiva únicamente (Kavanagh, Sitharthan, Young, Saunders, Shockley y Giannopoulos, 2006). Por otro lado, plantea problemas en cuanto a su generalización en diferentes contextos (Alter, 2002).

\section{CONCLUSIONES}

En el presente artículo hemos resumido aquellos aspectos más relevantes para la comprensión y el estudio del craving por la nicotina. Se ha realizado un breve recorrido por los modelos explicativos más relevantes desde un punto de vista psicológico, así como aspectos relacionados con la evaluación y el tratamiento del craving por la nicotina. A modo de resumen, señalar que el constructo craving ha sido un concepto polémico en su desarrollo. La ausencia de definiciones operativas ha llevado a convertirlo en un "cajón desastre", que abarcaba otros fenómenos relacionados con la adicción pero independientes del craving. Los diferentes modelos explicativos ponen de manifiesto la necesidad de un mode- 
lo que use un lenguaje común y medidas estandarizadas. A pesar de estar aún lejos de ofrecer un modelo unificado del fenómeno craving, las investigaciones que desde la neurociencia y la psicología se están realizando contribuyen de manera decisiva a avanzar en el conocimiento y tratamiento del ansia por el tabaco. Este modelo debería integrar los avances realizados desde las diferentes disciplinas, así como los estudios realizados con diferentes técnicas, empleando tanto animales como humanos. En los últimos años, se están realizando importantes esfuerzos en esta dirección. La integración de múltiples disciplinas tiene un potencial enorme ya que proporcionan nuevos ángulos de visión para futuras investigaciones sobre el craving. Así mismo, debe existir un intercambio continuo entre la investigación básica y la observación clínica, que abra nuevas vías en el conocimiento de la etiología y tratamiento del craving.

Sin duda, a una de las primeras preguntas que debe responder este modelo unificado es el carácter afectivo del craving. Mientras que unos modelos asumen que éste es consecuencia de un estado emocional negativo, otros postulan la existencia de un estado emocional positivo. Por último, un tercer grupo diferencian los aspectos afectivos del craving, de modo que la aparición de éste no viene condicionada, aunque sí modulada, por el estado emocional. Conocer la relación entre emociones y craving poedría abrir la puerta a nuevos enfoques psicológicos, que podrían revelar nuevas estrategias en el manejo del craving en fumadores.

Otro aspecto importante, es el desarrollo de métodos para medir el craving, libres de variables contaminadoras y que se ajusten a los diferentes paradigmas experimentales 0 entornos naturales. Las escalas multidimensionales pueden ser útiles cuando se precise una evaluación amplia y precisa de los distintos aspectos implicados en el craving por el tabaco en un contexto clínico. Las escalas unidimensionales, sin embargo, podrian estar indicadas en contextos naturales, cuando sea necesaria una evaluación fácil y rápida por parte del paciente del deseo que experimentan ante una situación concreta.

Las estrategias terapéuticas para el control del craving deben tener en cuenta tanto los aspectos psicológicos como neuroquímicos implicados en el craving. Aunque es necesario un mayor desarrollo de fármacos anti-craving, los actuales ayudan a controlar el deseo por fumar, resultando de utilidad en las primeras fases del abandono del tabaquismo. En la actualidad disponemos de sustancias que los clínicos pueden emplear como fármacos de primera línea en el tratamiento del craving, como son los sustitutos de nicotina (parches, chicles, spray...), el Bupropion o la Vareniclina. Otros fármacos, son considerados tratamientos de segunda elección o se tratan de sustancias en fase experimental. En cualquier caso, este tratamiento farmacológico debe ser acompañado de tratamiento psicológico. El entrenamiento en técnicas psicológicas destinadas al manejo del craving resulta relevante ya que el craving se mantiene a lo largo del tiempo y unas correctas habilidades de afrontamiento pueden evitar la recaída y mantener la abstinencia.

A pesar que en los últimos años se ha avanzado considerablemente en la investigación del fenómeno craving, aún quedan por dilucidar muchas cuestiones en torno a los mecanismos que subyacen al mismo. Por ello, resulta totalmente necesario comprobar las hipótesis que se desprenden de la literatura revisada así como otras que no han podido ser recogidas en estas páginas. Además, por la importancia que tiene el craving en el tratamiento del tabaquismo, resulta necesario evaluar el alcance clínico de las propuestas y sugerencias que se extraen de los estudios experimentales recogidos. La comprobación de las hipótesis que se desprenden de la literatura mediante estudios clínicos, permitirá abordar con mayores garantías de éxito las demandas asistenciales en el tratamiento del tabaquismo.

\section{AGRADECIMIENTOS}

El presente trabajo ha contado con la financiación del Ministerio de Sanidad y Consumo (MSC2005-7179) a J.V. y el Ministerio de Educación y Ciencia (SEJ2007-62312) a P.M., y (JCl-2008-03074) a M.A.M.

\section{REFERENCIAS}

Allen, S.S., Bade, T., Hatsukami, D. y Center, B. (2008). Craving, withdrawal, and smoking urges on days immediately prior to smoking relapse. Nicotine \& Tobacco Research, 10, 35-45.

Altner, N. (2002). Mindfulness Practice and Smoking Cessation: The Essen Hospital Smoking Cessation Study. Journal for Meditation and Meditation Research, 2, 9-18.

Ashelman, M.W. (2000). Stop Smoking Naturally. New Canaan, Connecticut: Keats Publishing Inc.

Antón, R.F. (1999). What is craving? Models and implications for treatment. Alcohol Research and Health, 23,165-73.

Baker, T.B., Piper, M.E., McCarthy, D.E., Majeskie, M.R. y Fiore, M.C. (2004). Addiction motivation reformulated: an affective processing model of negative reinforcement. Psychological Review, 111, 33-51.

Baker, T.B., Morse, E. y Sherman, J.E. (1986). The motivation to use drugs: A psychobiological analysis of urges. Nebraska Symposium on Motivation, 34, 257-323.

Balfour, D. J. K. (2005). The neurobiology of tobacco dependence: A preclinical perspective on the role of the dopamine projections to the nucleus. Nicotine and Tobacco Research, 6, 899-912.

Baxter, M.G. y Murray, E.A. (2002). The Amygdala and Reward. Nature Reviews Neuroscience 3, 563-573.

Benowitz, N.L. (1998). Pharmacology aspects of cigarette smoking and nicotine addiction. National England Journal of Medicine, 319, 1318-1330.

Benowitz, N.L. (2008a). Neurobiology of nicotine addiction: Implications for smoking cessation treatment. The American Journal of Medicine, 121(supl. 1), S3-S10.

Benowitz, N.L. (2008b) Clinical Pharmacology of Nicotine: Implications for Understanding, Preventing, and Treating Tobacco Addiction. Clinical Pharmacology y Therapeutics, 83, 531-541. 
Berridge, K. C. (2007). The debate over dopamine's role in reward: the case for incentive salience. Psychopharmacology, 191, 391-431.

Berridge, K. C. y Robinson, T. E. (1998). What is the role of dopamine in reward: Hedonic impact, reward learning, or incentive salience? Brain Research Reviews, 28, 309-369.

Berridge, K.C., Robinson, T.E. y Aldridge, J.W. (2009). Dissecting components of reward: 'liking', 'wanting', and learning. Current Opinion in Pharmacology, 9, 65-73.

Blasco, J., Martínez-Raga, J., Carrasco, E. y Didia-Attas, J. (2008). Atención y craving o ganas compulsivas. Avances en su conceptualización y su implicación en la prevención de recaídas. Adicciones, 20, 365-376.

Bond, A. y Lader, M. (1974). The use of analogue scales in rating subjective feelings. British Journal of Medical Psychology, 47, 211-218.

Brody, A. L., Mandelkern, M. A., London, E. D., Childress, A. R., Lee, G. S., Bota, R. G., ...Jarvik, M. E. (2002). Brain metabolic changes during cigarette craving. Archives of General Psychiatry, 59, 1162-1172.

Brown, K.W. y Ryan, R.M. (2003). The benefits of being present: mindfulness and its role in psychological well-being. Journal of personality and social psychology, 84, 822-848.

Cardinal, R., Parkinson, J., Hall, J. y Everitt, B. (2002). Emotion and motivation: the role of the amygdala, ventral striatum and prefrontal cortex. Neuroscience and Biobehavioral Reviews, 26, 321-352.

Cepeda-Benito, A. (1993). A meta analytical review of the efficacy of nicotine chewing gum in smoking treatment programs. Journal of Consulting and Clinical Psychology, 61, 822-830.

Chiamulera, C. (2005). Cue reactivity in nicotine and tobacco dependence: a "multiple-action" model of nicotine as a primary reinforcement and as an enhancer of the effects of smokingassociated stimuli. Brain Research Reviews, 48, 74-97.

Cinciripini, P.M., Lapitsky, L., Seay, S., Wallfisch, A., Meyer, W.J. y van Vunakis, H. (1995). A placebo- controlled evaluation of the effects of buspirone on smoking cessation: differences between high- and low-anxiety smokers. Journal of Clinical Psychopharmacology, 15, 182-191.

Conklin, C. A., Clayton, R. R., Tiffany, S. T., y Shiffman, S. (2004). Introduction to concepts and measurement of the emergence of tobacco dependence: The Tobacco Etiology Research Network. Addiction, 99 (Suppl. 1), 1-4.

Covey, L.S., Glassman, A.H., Stetner, F., Rivelli, S. y Stage, K. (2002). A randomized trial of sertraline as a cessation aid for smokers with a history of major depression. American Journal of Psychiatry, 159, 1731- 7

Davis, J.M., Fleming, M.F., Bonus, K.A., y Baker, T.B. (2007). A pilot study on mindfulness based stress reduction for smokers $B M C$ Complementary and Alternative Medicine, 7, 1-7.

Davis, M. (1992). The role of the amygdala in conditioned fear. En J. P. Aggleton (Ed.), The amygdala: Neurobiological aspects of emotion, memory, and mental dysfunction (pp. 255-305). New York: Wiley-Liss.
Di Ciano, P., y Everitt, B. J. (2004). Direct Interactions between the Basolateral Amygdala and Nucleus Accumbens Core Underlie Cocaine-Seeking Behavior by Rats. Journal of Neuroscience, 24, 7167-7173.

Drobes, D. J. (2002). Cue reactivity in alcohol and tobacco dependence. Alcoholism: Clinical and Experimental Research, 26, 1928-1929.

Drummond, D.C. (2001) Theories of drug craving ancient and modern. Addiction, 96, 33-46.

Drummond, D. C., Tiffany, S. T., Glautier, S. y Remington, B. (1995). Addictive behaviour: Cue exposure theory and practice. UK: Wiley \& Sons.

Due, D. L., Huettel, S. A., Hall, W. G. y Rubin, D. C. (2002). Activation in mesolimbic and visuospatial neural circuits elicited by smoking cues: Evidence from functional magnetic resonance imaging. American Journal of Psychiatry, 159, 954-960.

Dunn, L. T., y Everitt, B. J. (1988). Double dissociations of the effects of amygdala and insular cortex lesions on conditioned taste aversion, passive avoidance, and neophobia in the rat using the excitotoxin ibotenic acid. Behavioral Neuroscience, 102, 3-23.

Ebbert, J.O., Croghan, I.T., Sood, A., Schroeder, D.R., Hays, J.T. y Hurt, R.D. (2009). Varenicline and bupropion sustained-release combination therapy for smoking cessation. Nicotine Tobacco Research. Advance online publication. DOI: 10.1093/ntr/ntn031.

Everitt, B. J., Parkinson, J. A., Olmstead, M. C., Arroyo, M., Robledo, P., y Robbins, T.W. (1999). Associative processes in addiction and reward: The role of amygdalaventral striatal subsystems. Annals of the New York Academy of Sciences, 877, 412-438.

Everitt, B. J., y Robbins, T. W. (2005). Neural systems of reinforcement for drug addiction: From actions to habits to compulsion. Nature Neuroscience, 8, 1481-1489.

Everitt, B.J. y Robbins, T.W. (1992). Amygdala-ventral striated interactions and reward related processes. En L. Aggleton (Ed.), The amygdala: Neurobiological aspects of emotion, memory, and mental dysfunction (pp. 401-429). New York: Wiley.

Field, M., Rush, M., Cole, J. y Goudie, A.J. (2007). The smoking Stroop and delay discounting in smokers: effects of environmental smoking cues. Journal Psychopharmacology, 21, 603-610

Fiore, M.C., Jaén, C.R., Baker, T.B., Bailey, W.C., Benowitz, N.L., Curry, S.J.,... Wewers, M.E. (2008). Treating Tobacco Use and Dependence: 2008 Update. Clinical Practice Guideline. Rockville, MD: U.S. Department of Health and Human Services. Public Health Service. http://www.surgeongeneral.gov/tobacco/ treating_tobacco_use08.pdf

Frazer, A. (2001). Serotonergic and Noradrenergic reuptake inhibitors: prediction of clinical effects from in vitro potencies. Journal of Clinical Psychiatry, 62,16-23.

Gifford, E.V., Kohlenberg, B.S., Hayes, S.C., Antonuccio, D.O., Piasecki, M.M., Rasmussen-Hall, M. y Palm, K.M. (2004). Acceptancebased treatment for smoking cessation. Behaviour Therapy, 35, 689-705.

Glassman, A.H., Covey, L.S., Dalack, G.W., Stetner, F., Rivelli, S.K., Fleiss, J. y Cooper, T.B. (1993). Smoking cessation, clonidine, and vulnerability to nicotine among dependent smokers. Clinical Pharmacology Therapy, 54, 670-679. 
Gloria, R., Angelos, L., Schaefer, H.S., Davis, J.M., Majeskie, M., Richmond, B.S.,...Baker, T.B.(2009). An fMRI investigation of the impact of withdrawal on regional brain activity during nicotine anticipation. Psychophysiology, 46, 681-693.

Goldstein, R.Z. y Volkow, N.D. (2002). Drug addiction and its underlying neurobiological basis: Neuroimaging evidence for the involvement of the frontal cortex. American Journal of Psychiatry, 159, 1642-1652.

Gourlay, S.G. y Benowitz, N.L. (1995). Is clonidine an effective smoking cessation therapy? Drugs, 50, 197-207.

Gray, M.A. y Critchley, H.D. (2007). Interoceptive Basis to Craving. Neuron, 54, 183-186,

Groenewegen, H.J., Berendse, H.W. y Haber, S.N. (1993) Organization of the output of the ventral striatopallidal system in the rat: ventral pallidal efferents. Neuroscience, 57, 113-142.

Hatsukami, D. K., Ebbert, J. O., Anderson, A., Lin, H., Le, C. y Hecht, S.S. (2007). Smokeless tobacco brand switching: A means to reduce toxicant exposure? Drug and Alcohol Dependence, 87, 217-224.

Henningfield, J.E. (1995). Nicotine medications for smoking cessation. New England Journal of Medicine, 333, 1196 -1203.

Henningfield, J.E. Fant, R.V. y Buchhalter, A.R. (2005). Pharmacotherapy for nicotine dependence. CA Cancer Journal Clinical, 55, 281-99.

Herrero, F. J. y Moreno, J. (2004). Tratamientos combinados del tabaquismo: psicológicos y farmacológicos. Adicciones, 16, 285301.

Hughes, J.R., Stead, L.F. y Lancaster, T. (2007). Antidepressants for smoking cessation. Cochrane Database of Systematic Reviews, 1, CD000031.

Iraurgi, I. y Corcuera, N. (2008). Craving: concepto, medición y terapéutica. Norte de Salud Mental, 32, 9-22.

Jané, M. (2004). Mujeres y tabaco: aspectos principales específicos de género. Adicciones, 16, 115-130.

Janse van Rensburg, K., Taylor, A.H. y Hodgson, T. (2007).The effects of exercise on regional brain activation in response to smoking cues during temporary abstinence from smoking [resumen]. 12th European Congress of Sport Psychology, Halkidiki, Greece.

Janse van Rensburg, K., Taylor, A.H. y Hodgson, T. (2008) The effects of acute exercise on attentional biases to smoking related stimuli during temporary abstinence from smoking. Addiction, 104, 1910 - 1917.

Jiménez, L., Bascarán, M. T., García-Portilla, M.P. Sáiz, M. A., Bousoño, M. y Bobes, J. (2004). La nicotina como droga. Adicciones, 16 (Supl.2), 143-153

Joel, D. y Weiner, I. (2000). The connections of the dopaminergic system with the striatum in rats and primates: An analysis with respect to the functional and compartmental organization of the striatum, Neuroscience, 96, 451-474.

Jorenby, D.E., Hays, J.T., Rigotti, N.A., Azoulay, S., Watsky, E.J., Williams K.E.,...Reeves, K.R. (2006). Efficacy of varenicline, an alpha4beta2 nicotinic acetylcholine receptor partial agonist, vs placebo or sustained-release bupropion for smoking cessation: a randomized controlled trial. JAMA, 296, 56-63.
Kalivas, P. W. y Volkow, N. D. (2005). The Neural Basis of Addiction: A Pathology of Motivation and Choice. American Journal of Psychiatry, 162, 1403-1413.

Kavanagh, D. J., Sitharthan, G., Young, R. M., Sitharthan, T., Saunders, J. B., Shockley, N. y Giannopoulos, V. (2006). Addiction of cue exposure to cognitive-behaviour therapy for alcohol misuse: a randomized trial with dysphoric drinkers. Addiction, 101, 11061116.

Kelley, A. E. (2004). Memory and Addiction: Shared Neural Circuitry and Molecular Mechanisms. Neuron, 44, 161-179.

Kober, H., Kross, E.F., Mischel, W., Hart, C.L. y Ochsner, K.N. (2010). Regulation of craving by cognitive strategies in cigarette smokers. Drug and Alcohol Dependence, 106, 52-55.

Lerman, C., Niaura, R., Collins, B. N., Wileyto, P., Audrain-McGovern, J., Pinto, A.,... Epstein, L. H. (2004). Effect of bupropion on depression symptoms in a smoking cessation clinical trial. Psychological Addictive Behaviour, 18, 362-366.

Lim, H. K., Pae, C. U., Joo, R. H., Yoo, S. S., Choi, B. G., Kim, D. J., ... Lee, C.U.(2005). fMRI investigation on cue-induced smoking craving. Journal of Psychiatric Research, 39, 333-335.

Livingstone, P.D. y Wonnacott, S. (2009). Nicotinic acetylcholine receptors and the ascending dopamine pathways, Biochemical Pharmacology, 78, 744-55

Ludwig, A.M. y Wikler, A. (1974). Craving and relapse to drink. Quarterly Journal of Studies on Alcoholism, 35, 108-130.

Merikle, E.P (1999). The subjective experience of craving: an exploratory analysis. Substance Use and Misuse, 34, 1101-1115

Markou, A., Weiss, F., Gold, L.H., Caine, B., Schulteis, G. y Koob, G.F. (1993). Animal models of drug craving. Psychopharmacology, $112,63-182$.

Marlatt, G. A. (1985). Relapse prevention: theoretical rationale and overview of the model. En Marlatt, G. A. y Gordon, J. R. (Eds.). Relapse prevention, (pp. 3-70). New York: The Guilford Press.

Matsumoto, K., Suzuki, W. y Tanaka, K. (2003). Neuronal correlates of goal-based motor selection in the prefrontal cortex. Science, 301, 229-32.

Mihalak, K.B., Carroll, F.I. y Luetje, C.W. (2006). Varenicline is a partial agonist at alpha4beta2 and a full agonist at alpha7 neuronal nicotinic receptors. Molecular Pharmacology, 70, 801-5.

Miller, E.K., y Cohen, J.D. (2001). An integrative theory of prefrontal cortex function. Annual Reviews Neuroscience, 24,167-202.

Muñoz, M.A., Baena, A. y Cepeda-Benito, A. (2006). Revisión de tratamiento de tabaco en mujeres. Clínica y Salud, 17, 91-117.

Muñoz, M.A., Martinez, J.A. Fernández, M.C., Cepeda-Benito, C. y Vila, J. (2010). Two Scales to Evaluate Cocaine Craving. Substance Use y Misuse, 45, 1303-1318.

Muñoz, M.A., Viedma-del-Jesus, M.I., Fernández-Santaella, M.C., Peralta-Ramírez.M.I, Cepeda-Benito A. y Vila, J. (2009). Assessment of tobacco craving by means of the affective image visualization paradigm. Motivation and Emotion. Advance online publication. DOI- 10.1007/s11031-009-9145.

Murphy, J.K., Edwards, N.B., Downs, A.D., Ackerman, B.J. y Rosenthal, T.L. (1990). Effects of doxepin on withdrawal symptoms in 
smoking cessation. American Journal Psychiatry, 147, 13531357.

Nana, A. y Praditsuwan, R. (1998). Clonidine for smoking cessation. Journal of The Medical Association of Thailand, 81, 87-93.

Napier, T.C., Mitrovic, I., Churchill, L., Klitenick, MA, Lu, X.Y. y Kalivas, P.W. (1995). Substance $P$ in the ventral pallidum: projection from the ventral striatum, and electrophysiological and behavioral consequences of pallidal substance P. Neuroscience, $69,59-70$.

Naqvi, N. H., Rudrauf, D., Damasio, H. y Bechara, A. (2007). Damage to the insula disrupts addiction to cigarette smoking. Science, 315(5811), 531-534.

Niaura, R. Spring, B. Borrelli, B. Hedeker, D. Goldstein, M.G., Keuthen, N.,... Abrams, D.B.(2002). Multicenter trial of fluoxetine as an adjunct to behavioural smoking cessation treatment. Journal of Consulting and Clinical Psychology, 70, 887-896.

Niaura, R. (2008). Nonpharmacologic Therapy for Smoking Cessation: Characteristics and Efficacy of Current Approaches. American Journal of Medicine, 121, S11-S19.

Niaura, R., Abrams, D. B., Shadel, W. G., Rohsenow, D. J., Monti, P. M. y Sirota, A. D. (1999). Cue exposure treatment for smoking relapse prevention: a controlled clinical trial. Addiction, 94, 685-695.

Nides, M.(2008). Update on pharmacologic options for smoking cessation treatment. American Journal of Medicine, 121, S20S31.

O'Connor, E.C., Parker, D., Rollema, H. y Mead, A.N. (2010). The $\alpha 4 \beta 2$ nicotinic acetylcholine-receptor partial agonist varenicline inhibits both nicotine self-administration following repeated dosing and reinstatement of nicotine seeking in rats. Psychopharmacology, 208, 365-376.

OMS - Expert Committee on Mental Health and Alcohol. (1955). The "craving" for alcohol. Quarterly Journal of Studies on Alcohol, 16, 33-66.

Parkinson, J.A., Crofts, H.S., McGuigan, M., Tomic, D.L., Everitt, B.J. y Roberts, A.C. (2000). The role of the primate amygdala in conditioned reinforcement. Journal of Neuroscience 21, 7770 -7780 .

Parsons, A.C., Shraim, M., Inglis, J., Aveyard, P. y Hajek, P.(2009). Interventions for preventing weight gain after smoking cessation. Cochrane Database of Systematic Reviews 1, CD006219.

Pérez de los Cobos, J. C., Valderrama, J. C., Cervera, G. y Rubio, G. (2006). Tratado SET de trastornos adictivos (1 ed.). Madrid: Medica Panamericana.

Pettinati, H.M., Volpicelli, J.R., Kranzler, H.R., Luck, G., Rukstalis, M.R. y Cnaan, A. (2000). Sertraline treatment for alcohol dependence: interactive effects of medication and alcoholic subtype. Alcoholism Clinical and Experimental Research, 24, 1041-1049.

Pinet, C.(2003). Tratamiento del tabaquismo. En Bobes J, Casas M, Gutiérrez M (eds.). Manual de evaluación y tratamiento de drogodependencias. Barcelona: Ars Medica.

Pitkänen A. (2000). Connectivity of the rat amygdaloid complex. En Aggleton (Ed.), The Amygdala: A Functional Analysis, (pp. 31-115). UK: Oxford Univ.
Placzek, A.N., Zhang, T.A. y Dani, J.A. (2009) Nicotinic mechanisms influencing synaptic plasticity in the hippocampus. Acta Pharmacologica Sinica. 30, 752-60.

Poulos, C. X., Hinson, R. E. y Siegel, S. (1981). The role of Pavlovian processes in drug tolerance and dependence: implications for treatment. Additive Behaviours, 6, 205- 211.

Prochaska, J.J., Delucchi, K. y Hall, S.M. (2004). A meta-analysis of smoking cessation interventions with individuals in substance abuse treatment or recovery. Journal of Consulting and Clinical Psychology, 72, 1144-1156.

Quesada, M., Carreras, J. M. y Sánchez, L. (2002). Recaida En El Abandono Del Consumo De Tabaco: Una Revisión. Adicciones, 14, 65-78.

Ray, R., Tyndale, R.F. y Lerman, C. (2009). Nicotine dependence pharmacogenetics: Role of genetic variation in nicotinemetabolizing enzymes. Journal Neurogenetics, 23, 1-10.

Robbins, T.W. y Everitt, B.J. (1996). Neurobehavioural mechanisms of reward and motivation. Current Opinion Neurobiology, 6, 228236.

Robinson, T. E. y Berridge, K. C. (1993). The neural basis of drug craving: An incentive-sensitization theory of addiction. Brain Research Reviews, 18, 247-291.

Roesch, M.R. y Olson, C.R. (2004). Neuronal activity related to reward value and motivation in primate frontal cortex. Science, 304, $307-10$.

Rose, J.E. (2007). Multiple brain pathways and receptors underlying tobacco addiction. Biochemical Pharmacology, 74, 1263-1270.

Rosse, R.B., Johri, S., Kendrick, K., Hess, A.L., Alim, T.N., Miller, M.M. y Deutsch, S.I. (1997). Preattentive and attentive eye movements during visual scanning of a cocaine cue: Correlation with intensity of cocaine craving. Journal of Neuropsychiatry and Clinical Neurosciences, 9, 91-93.

Sáiz, P. A., Garcia-Portilla, M. P., Martínez, S., Bascarán, M. T., Paredes, B. y Bobes, J. (2004). Tratamiento farmacológico. Psicofármacos. Adicciones, 16 (Supl. 2), 275-286

Sayette, M. A., Shiffman, S., Tiffany, S. T., Niaura, R. S., Martin, C. S. y Shadel, W. G. (2000) The measurement of drug craving, Addiction, 95 (Suppl. 2), S189-S210.

Sayette, M. y Hufford, M. (1994). The effects of cue exposure and deprivation in cognitive resources in smokers. Journal of Abnormal Psychology, 103, 812-818.

Schneider, N.G., Lunell, E., Olmstead, R.E. y Fagerstrom, K.O. (1996). Clinical pharmacokinetics of nasal nicotine delivery. A review and comparison to other nicotine systems. Clinical Pharmacokinetics, 31, 65-80.

Selden, N. R. W., Everitt, B. J., Jarrard, L. E. y Robbins, T. W. (1991). Complementary roles for the amygdala and hippocampus in aversive conditioning to explicit and contextual cues. Neuroscience, 42, 335-350.

Shadel, W., Niaura, R. y Abrams, D. (2001). Does completing a craving questionnaire promote increased smoking craving? An experimental investigation. Psychology of Addictive Behaviors, $15,265-267$. 
Sharma, A. y Brody, A.L. (2009). In vivo Brain Imaging of Human Exposure to Nicotine and Tobacco. En Henningfield, J.E., London E.D. and Pogun, S. (Eds) Nicotine Psychopharmacology Handbook of Experimental Pharmacology 192, Berlin: Heidelberg.

Shidara, M. y Richmond, B.J. (2002). Anterior cingulate: single neuronal signals related to degree of reward expectancy. Science, 296, 1709-1711.

Shiffman, S. (1984). Coping with temptations to smoke to smoke. Journal of consulting and clinical psychology, 52, 261-307.

Shiffman, S., West, R. J., y Gilbert, D.G. (2004). Recommendation for the assessment of tobacco craving and withdrawal in smoking cessation trials. Nicotine and Tobacco Research, 6, 599-614.

Siegel, S. (1979). The role of conditioning in drug tolerance and addiction. En J.D. Keehn (Ed.). Psychopathology in animals: research and treatment implications. New York: Academic Press.

Sociedad Española de Psiquiatría (2003). Consenso de la Sociedad Española de Psiquiatría sobre diagnóstico y tratamiento del alcoholismo y otras adicciones. Barcelona: Euromedice, 2003.

Stewart, J., De Wit, H. y Eilkelboom, R. (1984). Role of unconditioned and conditioned drug effects in self-administration of opiates and stimulants. Psychological Review, 91, 251-268.

Stoehr, J. D. (2006). The neurobiology of Addiction. Philadelphia: Chelsea House.

Taylor, A.H. y Katomeri, M. (2007). Walking reduces cue-elicited cigarette cravings and withdrawal symptoms, and delays ad libitum smoking. Nicotine \& Tobacco Research, 9, 1-8.

Tejero, A., Trujols, J. y Siñol, N.(2003). Evaluación del craving a la cocaina. En Pérez de los Cobos, J. (Ed.): Instrumentos clínicos para la evaluación de la dependencia a la cocaina. Barcelona: Citran-Ars Medica.

Tiffany, S. T. (1990). A cognitive model of drug urges and drug-use behavior: Role of automatic and nonautomatic processes. Psychological Review, 97, 147-168.

Tiffany, S. T. (1997). New perspectives on the measurement, manipulation and meaning of drug craving. Human Psychopharmacology: Clinical and Experimental, 12, 103-113.

Tiffany, S.T. (1995). The role of cognitive factors in reactivity to drug cues. En Drummond, D.C., Tiffany, S.T., Glautier, S.P. and Remington, B. (Eds.): Addictive behaviour: Cue Exposure, Theory and Practice (pp. 137-169). Chichester, England: John Wiley.

Tiffany, S.T. y Drobes, D.J. (1991). The development and initial validation of a questionnaire of smoking urges. British Journal of addiction, 86, 1467-1476.

Tiffany, S.T. (1992). A critique of contemporary urge and craving research: methodological, psychometric, and theoretical issues. Advances in Behaviour Research and Therapy, 14, 123-139.

Tonstad, S. (2006). Smoking cessation efficacy and safety of varenicline, an alpha4beta2 nicotinic receptor partial agonist. Journal Cardiovascular Nursing, 21, 433-436.
U.S. Department of Health \& Human Services.(2008). Treating Tobacco Use and Dependence:2008 Update. A report of the Surgeon General. Rockville, MD: Public Health Service.

Ussher, M.H., Taylor, A. y Faulkner, G.(2008). Exercise interventions for smoking cessation. Cochrane Database of Systematic Reviews, 4, CD002295.

Vidrine, J.I., Businelle, M.S., Cinciripini, P., Li, Y., Marcus, M.T. , Waters, A.J., Reitzel, L.R. y Wetter, D.W.(2009) Associations of Mindfulness with Nicotine Dependence, Withdrawal, and Agency, Substance Abuse, 30, 318-327.

Villegier, A. S., Salomon, L., Blanc, G., Godeheu, G., Glowinski, J. y Tassin, J. P. (2006). Irreversible blockade of monoamine oxidases reveals the critical role of 5 -HT transmission in locomotor response induced by nicotine in mice. European Journal of Neuroscience, 24, 1359-1365.

Watkins, S. S., Koob, G. F. y Markou, A. (2000). Neural mechanisms underlying nicotine addiction: Acute positive reinforcement and withdrawal. Nicotine and Tobacco Research, 2, 19-37.

Weiss, F.(2005). Neurobiology of craving, conditioned reward and relapse. Current Opinion of Pharmacology, 5, 9-19.

West, R.J.(2000) Signs and symptoms during the acute phase of smoking cessation. International Journal of Neuropsychopharmacology, 3, S59.

Wilson, S. J., Sayette, M. A., y Fiez, J. A. (2004). Prefrontal responses to drug cues: a neurocognitive analysis. Nature Neuroscience, 7. 211-214.

Winhusen, T., Somoza, E., Harrer, J., Mezinskis, J., Montgomery, M., Goldsmith, R.,... Elkashef, A.(2005). A placebo-controlled screening trial of tiagabine, sertraline, and donepezil as cocaine dependence treatments. Addiction, 100 (Suppl.1), 68-77.

Wise, R.A. y Bozarth, M.A. (1987). A Psychomotor stimulant theory of addiction. Psychological Review, 94, 469-492.

Wise, R.A. (2004). Drive, Incentive, and Reinforcement: The Antecedents and Consequences of Motivation. Nebraska Symposium on Motivation (Series), 50,159-195.

Wooltorton, J.R.A., Pidoplichko, V.I., Broide, R.S. y Dani, J.A. (2003). Differential Desensitization and Distribution of Nicotinic Acetylcholine Receptor Subtypes in Midbrain Dopamine Areas. Journal of Neuroscience, 23, 3176-3185.

Xi, Z.X., Spiller, K. y Gardner, E.L. (2009). Mechanism-based medication development for the treatment of nicotine dependence. Acta Pharmacologica Sinica, 30, 723-739.

Zanetti, L., Picciotto, M. R. y Zoli, M. (2007). Differential effects of nicotinic antagonists perfused into the nucleus accumbens or the ventral tegmental area on cocaine-induced dopamine release in the nucleus accumbens of mice. Psychopharmacolog., 190, 189-199.

Zhang, T., Zhang, L., Liang, Y., Siapas, A.G., Zhou, F.M. y Dani, J.A. (2009). Dopamine signaling differences in the nucleus accumbens and dorsal striatum exploited by nicotine. Journal of Neuroscience, 29, 4035-43. 
